\title{
Commentary: Preoperative $\beta$-blockers-One size does not fit all when considering management
}

\author{
Gal Levy, MD, and Vincent R. Conti, MD
}

\author{
From the Division of Cardiovascular and Thoracic Surgery, Department of Surgery, University of Texas Medical \\ Branch, Galveston, Tex. \\ Disclosures: Authors have nothing to disclose with regard to commercial support. \\ Received for publication Jan 4, 2019; accepted for publication Jan 7, 2019; available ahead of print Feb 10, 2019. \\ Address for reprints: Vincent R. Conti, MD, Division of Cardiovascular and Thoracic Surgery, Department of Sur- \\ gery, University of Texas Medical Branch, 301 University Blvd, Galveston, TX 77555 (E-mail: vconti@utmb. \\ edu). \\ J Thorac Cardiovasc Surg 2019;158:1600-1 \\ $0022-5223 / \$ 36.00$ \\ Copyright (c) 2019 by The American Association for Thoracic Surgery \\ https://doi.org/10.1016/j.jtcvs.2019.01.022
}

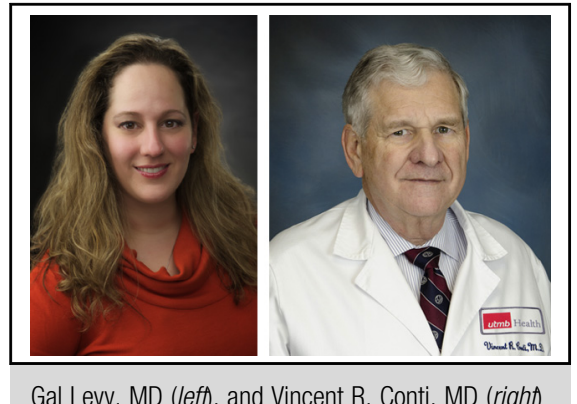

Gal Levy, MD (left), and Vincent R. Conti, MD (right)

Central Message

Both benefit and harm can occur from $\beta$ blocker therapy early after aortic valve replacement. Management directed at preventing the complications found here may well shift the effect to net benefit.

See Article page 1589. prevent cardiac related complications has been highly controversial. ${ }^{1-3}$ In the study in this issue of the Journal by Shubert and colleagues ${ }^{4}$ of patients undergoing isolated aortic valve surgery, a remarkable $53 \%$ of patients were receiving preoperative $\beta$-blocker therapy. The major question raised by Shubert and colleagues ${ }^{4}$ was whether this had a negative effect on the outcomes. They have previously raised the issue of whether the policy of requiring $\beta$-blocker use as a quality metric for coronary bypass grafting should be considered valid, even though it has been advocated by our major organizations. ${ }^{5}$ It is true that there is evidence to support the use of $\beta$-blockers for preoperative medical treatment in patients with severe aortic stenosis, ${ }^{6}$ and this may explain why such a high percentage of their patients were receiving preoperative $\beta$-blockers.

For accurate assessment of the consequences of the perioperative use of $\beta$-blocker, a study must include more than whether the patient was receiving the drug before the operative procedure. Shubert and colleagues ${ }^{4}$ point this out clearly in their list of limitations, which includes "which $\beta$-blockers and dosages were used, timing and duration of $\beta$-blocker therapy, heart rate and blood pressure variation, technical intraoperative details, or postoperative vasopressor requirements." They also have not specified what proportion of patients actually had $\beta$-blockers continued postoperatively and whether corrective interventions such as overdrive atrial pacing to optimize heart rates were used. There is also evidence that the type of $\beta$-blocker can have a significant effect on outcomes, ${ }^{7}$ and the types used were not specified.

It is also noted that in both groups of Shubert and colleagues, ${ }^{4}$ approximately $27 \%$ had moderate to severe aortic insufficiency. Although consideration of the pathophysiology of aortic insufficiency and the dependence on an adequate heart rate to optimize hemodynamics and prevent diastolic distention would suggest that $\beta$-blocker therapy would be detrimental, there is 1 study $^{8}$ that showed that it had a benefit as long as the heart rate was 70 beats/min or faster. That study, however, did not permit heart rate to be less than 70 in these patients. ${ }^{8}$ Because more than onequarter of their study group had significant aortic insufficiency, Shubert and colleagues ${ }^{4}$ should have verified that the preoperative heart rates were adequate to prevent these patients from entering the operation with compromised ventricles.

Although Shubert and colleagues ${ }^{4}$ clearly established 2 carefully matched groups to assess the effect of preoperative $\beta$-blockers versus no preoperative $\beta$-blockers, it remains unclear whether the $\beta$-blocker group may have had other risk factors, such as preoperative remote episodes of atrial fibrillation, to raise their risk or whether this same group had their $\beta$-blockers stopped early after operation, thus increasing their risk of atrial fibrillation from $\beta$-blocker withdrawal.

What this study strongly suggests is that when preoperative $\beta$-blockers are continued postoperatively, the dose and drug type should be chosen on an individual basis. Adequate heart rate and blood pressure should be maintained early in the postoperative period if necessary with atrial pacing and blood pressure control with vasopressors. In this way, the incidence of renal failure needing dialysis, the need for transfusion, and the incidence of atrial fibrillation and episodes of cardiac arrest may well be diminished. 


\section{References}

1. Chopra V, Plaisance B, Cavusoglu E, Flanders SA, Eagle KA. Perioperative betablockers for major noncardiac surgery: primum non nocere. Am J Med. 2009;122: 222-9.

2. Jorgensen ME, Hlatky MA, Køber L, Sanders RD, Torp-Pedersen C, Gislason GH, et al. $\beta$-Blocker-associated risks in patients with uncomplicated hypertension undergoing noncardiac surgery. JAMA Intern Med. 2015;175:1923-31. Erratum in: JAMA Intern Med. 2016;176:284.

3. Smilowitz NR, Berger JS. Perioperative management to reduce cardiovascular events. Circulation. 2016;133:1125-30.

4. Schubert SA, Hawkins RB, Mehaffey JH, Fonner CE, Rich JB, Speir AM, et al. Preoperative $\beta$-blocker use correlates with worse outcomes in patients undergoing aortic valve replacement. J Thorac Cardiovasc Surg. 2019;158:1589-97.e3.

5. LaPar DJ, Crosby IK, Kron IL, Kern JA, Fonner E Jr, Rich JB, et al. Preoperative beta-blocker use should not be a quality metric for coronary artery bypass grafting. Ann Thorac Surg. 2013;96:1539-44; discussion 1544-5.

6. Rossi A, Temporelli PL, Cicoira M, Gaibazzi N, Cioffi G, Nistri S, et al. Betablockers can improve survival in medically-treated patients with severe symptomatic aortic stenosis. Int J Cardiol. 2015;190:15-7.

7. Kertai MD, Esper SA, Akushevich I, Voora D, Ginsburg GS, Stafford-Smith M, et al; Cardiothoracic Anesthesia Research Endeavors (CARE) Group. Preoperative CYP2D6 metabolism-dependent $\beta$-blocker use and mortality after coronary artery bypass grafting surgery. J Thorac Cardiovasc Surg. 2014;147:1368-75.e3.

8. Sampat U, Varadarajan P, Turk R, Kamath A, Khandhar S, Pai RG. Effect of betablocker therapy on survival in patients with severe aortic regurgitation results from a cohort of 756 patients. J Am Coll Cardiol. 2009;54:452-7. 